\title{
TYMPANOPLASTY TYPE I USING TRAGAL CARTILAGE AS GRAFT: OUR EXPERIENCE.
}

1. MBBS, FCPS,

Assistant Professor

Department of ENT, Head and Neck Surgery

Medical Teaching Institute (MTI) Lady Reading Hospital (LRH), Peshawar -Khyber PakhtunkhwaPakistan.

2. MBBS, MCPS, FCPS

Associate Professor

Department of ENT

Rai Medical College Sargodha,

Punjab

Correspondence Address:

Dr. Fazal-I-Wahid

C-19, Khushal Medical Center,

Dabgari Garden Peshawer.

drfazal 58@yahoo.com

Article received on:

01/03/2019

Accepted for publication:

25/06/2019

\section{Fazal-I-Wahid', Sajid Rashid Nagra²}

ABSTRACT... Objectives: To determine the efficacy of tragal cartilage graft in tympanoplasty type I. Study Design: Quasi-experimental study. Setting: Department of ENT, Head and Neck Surgery, Medical Teaching Institute (MTI), Lady Reading Hospital (LRH), Peshawar, Pakistan. Period: From Jan. 2017 to Dec. 2017 (One Year). Material \& Methods: A total of forty four patient fulfilling inclusion criteria were included in this study. All the patients were assessed in terms of detail history, thorough examination focusing on ENT findings. Pure Tone Audiometry (PTA) was performed pre-operative and post-operative at 3 and 6 months interval for the frequencies of $0.5,1,2,4 \mathrm{~Hz}$. Data were analyzed using SPSS (version 16). Paired sample t-test of significance was used. The confidence interval was set to $95 \%$ and $P$-value $<0.05$ was considered significant. Results: Out of 44 patients males were 24 (54.54\%), female 20 (45.45\%) with Male: Female ratio of 1.2:1. Mean age of the patients was 28. 47 + SD 7.26 Years. There was statistically significant difference between the pre and post-op air conduction $(p<.001)$, and pre-op and post-op air bone gap $(p<.001)$.There was subjectively significant hearing improvement in 31 patients $(70.5 \%)$. Cartilage graft was taken in 43 patients with success rate of $97.7 \%$. Conclusion: Tragal cartilage is an effective graft material, which yields good results in terms of graft take up, hearing improvement and minimum complication, postoperative healing and acoustic properties.

Key words: $\quad$ Tragal Cartilage, Graft, Tympanoplasty.

Article Citation: Fazal-I-Wahid, Nagra SR. Tympanoplasty Type I using Tragal Cartilage as graft: Our experience. Professional Med J 2019; 26(12):2135-2140.

DOI: 10.29309/TPMJ/2019.26.12.3334

\section{INTRODUCION}

Tympanic membrane(TM) perforation is the defect produced in the ear drum due to trauma or infection, which leads into otorrhea and reduced hearing. Tympanoplasty is the surgical procedure performed to reconstruct the perforated tympanic membrane, deal with middle ear pathology and restore middle ear sound conducting mechanism. ${ }^{1}$ Chronic Otitis Media (COM) can be classified into mucosal (active or inactive) and squamous types (active or inactive). Tympanoplasty Type I is performed in case of inactive mucosal COM. ${ }^{2}$ The mechanism of biological graft materials is that they act as scaffold of tissue matrix to seal the perforation which subsequently revascularises and migration of fibroblast and epithelium takes place. The commonly used autologous graft materials are vein, fat, fascia lata, temporalis fascia, tragal perichondrium and cartilages. ${ }^{3}$ Temporalis facia and tragal perichondrium are most commonly used due to their anatomic proximity, compliance and translucency. To get closure of perforation and restore hearing caused by chronic suppurative otitis media, several trials were carried out since the 1600s. In 1952 Zollner and Wllestein introduced tympanoplasty using various graft materials and prosthesis for closure of TM and as ossicular substitute respectively. Salen from Sweden was probably the first surgeon who used cartilage as graft material for myringoplasty with acceptable good results. ${ }^{4}$ He used septal cartilage with intact mucoperichondrium on one side. Thus he obtained $92 \%$ success rate of closing the perforation with good hearing result. Later Heermann et al, introduced cartilage palisade graft for tympanoplasty labeled as Simmering Technique. ${ }^{3}$ The same time, Goodhill introduced the first cartilage perichondrium composite graft for closing TM perforation. In 1998, Eavey introduced another technique of 
using tragal cartilage with intact perichondrium on both side with good results. In the literature reported success rate of temporalis facia is 93 $-97 \% .^{5}$ While cartilage has been proved to be middle ear friendly and survives for long time because it is nourished mainly by diffusion. Thus it maintains its rigid quality resisting resorption and retraction even in case of severe Eustachian Tube malfunction. ${ }^{4}$ The use of cartilage has been established in cases of chronically dysfunction eustachian tube, adhesive otitis media, draining ears with large perforation and recurrent perforation of TM. In the literature reported successful take rate and improvement of hearing for cartilage tympanoplasty varies from $43 \%$ to $100 \% .^{5}$

Such study has never been conducted in our institute before. Moreover this study was aimed to test the effectiveness of tragal cartilage as graft in tympanoplasty type I in terms of graft take rate and postoperative audiometric results.

\section{MATERIALS AND METHODS}

This quasi-experimental study was conducted at the department of E.N.T, Head and Neck Surgery, Medical Teaching Institute (MTI), Lady Reading Hospital (LRH), Peshawar, Pakistan from Jan. 2017 to Dec. 2017. Sample size was calculated using G-Power software, considering a as $0.05, \beta$ as 0.1 and effect size 8.5, thus sample size was 44 . Convenient (Non-probability) sampling technique was adopted. This study was approved from Hospital Ethical Board. A well informed consent was taken from all the patients explaining them the procedure, its benefits, risks and outcomes.

\section{Inclusion Criteria}

1. All patients of both genders in the age range $16-60$ years.

2. Inactive mucosal COM remained dry for at least one month.

3. Conductive hearing loss with minimum AirBone Gap (ABG) of $10 \mathrm{~dB}$.

4. Middle ear is free of disease.

\section{Exclusion Criteria}

1. Attic and / or posterior retraction pocket with cholesteatoma.
2. Ossicular chain dysfunction and associated otogenic complication.

3. Patients under 16 years or above 60 years.

4. Active mucosal COM.

All the patients were assessed in terms of detail history, thorough examination focusing on ENT findings, relevant investigations, surgery and follow up. Ear was evaluated for side, size, site, margins of perforation, ear drum remnants, middle ear mucosal status and aural discharge. Any septic focus in the rest of ENT was addressed before surgery. Pure Tone Audiometry (PTA) was performed pre-operative and post-operative at 3 and 6 months interval. All PTAs were performed by same senior audiometrician using standard two channel clinical audiometer Amplaid 455 made Italy. PTA was performed for the frequencies of $0.5,1,2,4 \mathrm{kHz}$. Pre- and postoperative thresholds at $0.5,1,2,4 \mathrm{kHz}$ were recorded. The ABG was calculated in both pre- and postoperative PTA. Success of the procedure was characterized in terms of graft take, closure in AB-Gap and subjective hearing improvement. Tragal cartilage with intact mucoperichondrium on one side was used as graft material for tympanoplasty. All patients were followed up for at least 6 months and any complication encountered was recorded. The data were recorded on predesigned proforma.

Data were analyzed using SPSS (version 16). Quantitative data were expressed as mean \pm standard deviation (SD). Qualitative data were expressed as frequency and percentage. Paired sample t-test of significance was used when comparing between related samples. The confidence interval was set to $95 \%$ and the margin of error accepted was set to $5 \%$. So, the p-value was considered significant as the following: P-value $<0.05$ was considered significant. P-value $<0.001$ was considered as highly significant. P-value $>0.05$ was considered insignificant.

All tympanoplasties were performed by the author following well-established principles of ear surgery. Proper position of the patient was obtained after general anesthesia. Aseptic cleaning and draping carried out. The tragus was infiltrated with $2 \%$ lidocaine with 1:100,000 
epinephrine. An incision through the skin and cartilage was made on the medial side of the tragus, leaving at least $2 \mathrm{~mm}$ of cartilage in the dome of tragus to maintain its contour for cosmesis. The tragal cartilage with its perichondrium was harvested. Tragal cartilage is ideal one as it is thin, flat, easily and sufficiently available. The tragal cartilage was thinned out to $0.5 \mathrm{~mm}$ thickness using No.15 surgical blade. Perichondrium is left intact on side of the cartilage. A V-shaped notch is excised from the cartilage to accommodate the handle of malleus. End-aural approach to the middle ear with inlay technique of graft placement was adopted. After denuding the remnants of margins of perforation tympanomeatal flap was elevated starting $6 \mathrm{~mm}$ lateral to the margin from 3 to 9 O'clock position. The middle ear was meticulously examined and any pathological material was addressed. The cartilage graft was placed on a bed formed by putting few pieces of Gelfoam to avoid medialization of graft. The cartilage graft was placed in the plane medial to the remnant of TM. No space is left between posterior canal wall and the reconstructed TM. Tympanomeatal flap was repositioned. Gelfoam pieces were placed to stabilize the graft. Routine postsurgical care was exercised and antibiotic + steroid containing drops were prescribed in case of any suspicion of infection. All patients were called for follow -up visits on $1^{\text {st }}, 3^{\text {rd }}$ and $6^{\text {th }}$ months' interval. During follow up visit PTA, Otoscopic examination of TM and subjective hearing improvement were recorded.

\section{RESULTS}

Total 44 patients were enrolled in this study; Male 24(54.54\%), Female20(45.45\%) with Male: Female ratio of 1.2:1. Mean age of the patients was 28. 47 + SD 7.26 (Min. 16, Max. 40) years. Patients in $3^{\text {rd }}$ decade of life dominated $(36 \%)$ followed by $1^{\text {st }}$ and $2^{\text {nd }}$ decade. Tympanic membrane perforation was more common on right side involving 25 patients $(56.8 \%)$, anterio-inferior site was involved in 26 patients $(59.1 \%)$ with predominantly medium sized perforation found in 28 patients (63.6\%) (Table-I). The mean and Standard deviation of PTA finding was calculated and there was no difference between mean and SD of Pre-op and post-op Bone Conduction on PTA i.e. there was no effect of cartilage tympanoplasty on bone conduction of sound transmission. The preop mean air-conduction $49.65+11.53 \mathrm{~dB}$ was reduced to post-op mean air-conduction of 22.27 $+12.22 \mathrm{~dB}$. There was statistically significant difference between the pre and post-op air conduction $(p<.001)$. The pre-op mean air bone gap (PTA- ABG) was $34.31+10.95 \mathrm{~dB}$, which was also reduced to post-op mean air bone gap (PTA- ABG) of $7.34+5.82 \mathrm{~dB}$. By applying Paired Samples Test there was statistically significant difference between pre-op and post-op air bone gap $(\mathrm{P}<.001) \quad($ Table-II). Thus cartilage graft tympanoplasty produced good results in term of closure of air-bone gap. There was subjectively significant hearing improvement in 31 patients (70.5\%), while mild hearing improvement was observed in 9 cases $(20.5 \%)$. Cartilage graft was taken in 43 cases $(97.7 \%)$, while graft failure was noticed in one case (2.3\%). Graft infection was observed in 3 cases $(6.8 \%)$ that responded to antibiotics.

\begin{tabular}{|c|c|c|}
\hline \multicolumn{3}{|c|}{ Side of Ear } \\
\hline Side of Ear & Frequency & Percent \\
\hline Right Side & 25 & 56.8 \\
\hline Left Side & 16 & 36.4 \\
\hline Both side & 3 & 6.8 \\
\hline Total & 44 & 100.0 \\
\hline \multicolumn{3}{|c|}{ Site of Perforation } \\
\hline \multicolumn{3}{|l|}{ Site of Perforation } \\
\hline Anterio-superior & 8 & 18.2 \\
\hline Anterio-inferior & 26 & 59.1 \\
\hline Posterio-superior & 3 & 6.8 \\
\hline Posterio-inferior & 7 & 15.9 \\
\hline Total & 44 & 100.0 \\
\hline \multicolumn{3}{|c|}{ Size of Perforation } \\
\hline \multicolumn{3}{|c|}{ Size of Perforation } \\
\hline Small & 1 & 2.3 \\
\hline Medium & 28 & 63.6 \\
\hline Large & 11 & 25.0 \\
\hline Total perforation & 4 & 9.1 \\
\hline Total & 44 & 100.0 \\
\hline \multicolumn{3}{|c|}{$\begin{array}{c}\text { Table-I. Characteristics of tympanic membrane } \\
\text { perforation (n- } 44) .\end{array}$} \\
\hline
\end{tabular}




\begin{tabular}{|c|c|c|c|}
\hline & Pre-Op (Mean + SD) & Post-Op (Mean + SD) & P-Value \\
\hline Air Conduction on PTA & $49.65+11.53$ & $22.27+12.22$ & $<.001$ \\
\hline Air-Bone $\operatorname{Gap}(A B G)$ on PTA & $34.31+10.97$ & $7.34+5.82$ & $<.001$ \\
\hline
\end{tabular}

\section{DISCUSSION}

In this study 44 patients were enrolled; Male 24 (54.54\%), Female 20 (45.45\%) with Male: Female ratio of $1.2: 1$, that is in accordance with study of Myla, who also carried out tympanoplasty on 60 patients; male 25 and female 22 with male: female ratio of $1.1: 1.6$

Similarly Khan studied total 80 patients, of which male $54 \%$, female $46 \%$ with male: female ratio of 1.1: $1 .{ }^{7}$ However this male: female ratio differs from others studies where female dominate. ${ }^{8,9}$ The patients include in this study had mean age of $28.47+$ SD $7.26(>16<40)$ years and patients in $3^{\text {rd }}$ decade of life dominated ( $\mathrm{n}-16$, $36 \%)$. This simulates to study of Shanmugam, who reported mean age of patient was 28.6 years with majority of patients belonged to $3^{\text {rd }}$ decade of life. ${ }^{10}$ Similarly Ocak from turkey also found that mean age of patient was 31.1 years. ${ }^{6}$

I observed that tympanic membrane perforation was more common on right side $(56.8 \%)$, at anterio-inferior site $(59.1 \%)$ with predominantly medium sized perforation (63.6\%). This is in agreement with Khan's study, where majority of patient had TM perforation on right side $(61.25 \%)$, followed by left side (38.75\%) and medium size perforation was most common (42.5\%). ${ }^{7}$

Similarly Myla noted that majority of patient had TM perforation in anterior quadrant $(38.7 \%)$, followed by posterior quadrant of TM (8.3\%). ${ }^{6}$ Yegin from Brazil also carried out study on cartilage tympanoplasty in 2016 and found that right ear was commonly involved ( $n-17,44.7 \%)$ and medium sized perforation was common one $(\mathrm{n}-18,47.4 \%) .{ }^{11}$

The success of tympanoplasty was determined by closure of air-bone gap (ABG) on post-operative PTA, healing of the membrane perforation with tragal cartilage graft and subjective improvement of the patient's hearing. The mean and Standard deviation of PTA finding was calculated and there was no difference between mean and SD of preop and post-op Bone Conduction on PTA i.e. there was no effect of cartilage tympanoplasty on bone conduction of sound transmission. Similarly Dabhekar, Kadah and Guind also calculated mean + SD of the PTA finding to get results of their studies. ${ }^{9,12,13}$

In this study the mean pre-operative Air-bone Gap (ABG) and mean post-operative ABG on PTA was calculated and there was statistically significant closure in air-bone gap which is comparable to other studies. In current study there was subjectively significant hearing improvement in 31 patients $(70.5 \%)$, while mild hearing improvement was observed in 9 cases (20.5\%). Similarly in Myla's study there was significant hearing improvement in $65 \%$ patients and mild hearing improvement in $20 \%$ patients. ${ }^{6}$ Sood from India also reported that subjective hearing improvement was occurred in thirty five out of 40 patients $(87.5 \%){ }^{4}$

In Kumar's study hearing improvement accounted $50 \% .{ }^{14}$ Graft infection was observed in 3 cases $(6.8 \%)$ that responded to antibiotics and no other serious complication was recorded in this study which comparable to study of Shrikrishna, who also encountered infection of graft in one case (3.33\%). ${ }^{5}$ Cartilage graft was taken in 43 cases $(97.7 \%)$ in this study, which is comparable to other studies as listed in table below (Table-III). ${ }^{1-3,7,10-18}$

\section{CONCLUSION}

Tragal cartilage is an effective graft material, which yields acceptable results in terms of graft take up rate and hearing improvement, because tragal cartilage gives greater stability to remnants of tympanic membrane perforation and resistant to negative middle ear pressure.

Copyright $\odot 25$ June, 2019. 


\begin{tabular}{|c|c|c|c|c|c|c|c|}
\hline $\begin{array}{l}\text { Author of } \\
\text { Study }\end{array}$ & $\begin{array}{l}\text { No. of } \\
\text { Patients }\end{array}$ & $\begin{array}{l}\text { Year of } \\
\text { Study }\end{array}$ & $\begin{array}{l}\text { Pre-Op ABG } \\
\text { mean +/-SD }\end{array}$ & $\begin{array}{c}\text { Post- } \\
\text { OP ABG } \\
\text { mean +/- SD }\end{array}$ & Graft & P-Value & $\begin{array}{l}\text { Success } \\
\text { Rate }\end{array}$ \\
\hline Hosam ${ }^{1}$ & 25 & 2016 & $22.4+/-6.14$ & $14.8+/-10.2$ & Butterfly cartilage & $<0.001$ & $76 \%$. \\
\hline Chouhan² & 100 & 2013 & $26.4+/-10$ & $18+/-9$ & Tragal Cartilage & $<0.00003$ & $90 \%$ \\
\hline Ozdamar $^{3}$ & 40 & 2011 & $28.2+/-9.3$ & $17.3+/-10.5$ & Tragal Cartilage & $<0.000$ & $96 \%$ \\
\hline $\mathrm{Khan}^{7}$ & 80 & 2015 & $\begin{array}{l}32.464+/- \\
5.0220\end{array}$ & $\begin{array}{l}9.2131+/- \\
3.2823\end{array}$ & Sliced Tragal Cartilage & $<0.008$ & $100 \%$ \\
\hline $\begin{array}{l}\text { Shanmugam } \\
10\end{array}$ & 25 & 2017 & $\begin{array}{l}37.00+/- \\
4.33013\end{array}$ & $\begin{array}{l}25.80+/- \\
6.23832\end{array}$ & Tragal cartilage & $<0.001$ & $92 \%$ \\
\hline Yegïn ${ }^{11}$ & 247 & 2014 & $22.43+/-8.07$ & $14.93+/-8.69$ & Full-thickness cartilage & $<0.001$ & $91.3 \%$ \\
\hline Kadah $^{12}$ & 60 & 2017 & $\begin{array}{c}26.75+/- \\
11.39\end{array}$ & $12.25+/-7.69$ & $\begin{array}{l}\text { Full ThicknessTragal } \\
\text { Cartilage }\end{array}$ & $<0.001$ & $85 \%$ \\
\hline Guind $^{13}$ & 30 & 2015 & $30.15 \pm 5.42$ & $20.44 \pm 5.34$ & Full Thickness Cartilage & & $(93.33 \%$ \\
\hline Kumar ${ }^{14}$ & 60 & 2017 & $\begin{array}{l}43.24+/- \\
12.15\end{array}$ & $31.8+/-10.55$ & $\begin{array}{l}\text { Tragal cartilage } \\
\text { perichondrium }\end{array}$ & $<0.0001$ & $93 \%$ \\
\hline Gun ${ }^{15}$ & 27 & 2013 & $25.48+/-3.69$ & $16+/-10.22$ & Cartilage Palisades & $<0.001$ & $96.7 \%$. \\
\hline Siddique ${ }^{16}$ & 35 & 2015 & $\begin{array}{c}39.00+/- \\
7.526\end{array}$ & $\begin{array}{c}30.94+/- \\
11.308\end{array}$ & Tragal cartilage & $<.000$ & $97.6 \%$ \\
\hline Kaya ${ }^{17}$ & 93 & 2014 & $22.1+/-7.1$ & $13.3+/-5.9$ & Butterfly Cartilage & $<0.05$ & $94.6 \%$ \\
\hline Yegin ${ }^{18}$ & 78 & 2014 & $\begin{array}{l}35.68+/- \\
12.94\end{array}$ & $\begin{array}{l}26.113+/- \\
12.87\end{array}$ & Full-thickness cartilage & $<0.001$ & $92.1 \%$ \\
\hline $\begin{array}{l}\text { Current } \\
\text { Study }\end{array}$ & 44 & 2017 & $\begin{array}{l}34.3182+/- \\
10.975\end{array}$ & $\begin{array}{l}7.340+/- \\
5.826\end{array}$ & Tragal Cartilage & $<.001$ & $97.7 \%$ \\
\hline
\end{tabular}

Table-III. Comparison of success rate of cartilage graft of our study with other studies.

\section{REFERENCES}

1. Hosam M, Shaker M, Aboulwafa A. Endoscopic inlay butterfly cartilage myringoplasty for central perforation. International Journal of Multidisciplinary Research and Development. 2017; 4(1) 107-10.

2. Chouhan A, Singh BK, Verma PC. Role of cartilage as a graft material for tympanic membrane and in middle ear reconstruction. International Journal of Otolaryngology and Head \& Neck Surgery. 2015 Feb 26;4(02):66.

3. Ozdamar K, Taskin U, Aydin S, Oktay MF, Guntekin $B$, Yucebas $K$ et al. Long-Term, high-frequency tympanometry and audiometry results after cartilage and fascia tympanoplasty. Turk Arch Otolaryngol 2014; 52: 43-6.

4. Sood AS, Pal P, Singla A. Comparative study of type I tympanoplasty using temporalis fascia and tragal cartilage with perichondrium as graft material. Int $\mathrm{J}$ Otorhinolaryngol Head Neck Surg 2018; 4:789-93.

5. Malik SA. Permeatal approach for tympanoplasty: Scar-less approach of external auditory canal integrity. JLUMHS 2014; 13(2):76-78.
6. Myla S, Elma R. Clinical study of results of myringoplasty with tragal perichondrium. International Journal of Science and Research (IJSR). 2016; 5(5): 1829-31.

7. Khan MN, Nath K, Talukdar B. Role of composite graft in type 1 tympanoplasty. Journal of Science, 2017; 7(4):168-172. DOI: http://dx.doi.org/10.21276/ jos.2017.7.4.4.

8. Shekharappa MK, Siddappa SM. Cartilage Myringoplasty: An Ideal Grafting Technique for Complex Perforations. Journal of Clinical and Diagnostic Research. 2017; 11(7): 6-8 DOI: 10.7860/ JCDR/2017/26877.10264.

9. Dabhekar DSB, Doifode DPV, Deshpande DAS. Cartilage tympanoplasty: A method for hearing reconstruction. Indian Journal of Basic and Applied Medical Research. 2016; 5(4):67-76.

10. Shanmugam R, Madhu A. Shanmugan VU, Mariappan R, Swaminathan B and Nivas RP. A study of audiological and surgical outcome of trgal cartilage graft myringoplasty. International Journal of Current Medical Sciences 2017; 7(10) 296-98. 
11. Yegin Y, Celik M, Koc AK, Kufeciler L, Elbistanlı MS, Kayhan FT. Comparison of temporalis fascia muscle and full-thickness cartilage grafts in type 1 pediatric tympanoplasties. Braz J Otorhinolaryngol. 2016; 82:695-701.

12. Kadah SMS, Abd-Elgaber FM, Abu-Elnasr A, AbuMossalem W. Full Thickness versus partial thickness tragal cartilage graft compared with temporalis muscle fascia graft in myringoplasty. Research in Otolaryngology, 2018 7(2): 21-27 DOI: 10.5923/j. otolaryn.20180702.01.

13. Guindi SS, Abd el-moez MK, Hussein MA, Magdy IM. Evaluation of healing and hearing results of full thickness cartilage graft versus partial thickness cartilage graft in tympanoplasty Med. J. Cairo Univ. 2016; 84(1): 679-84.

14. Kumar A, Narayan P, Narain P, Singh J, Porwal PK, Sharma $S$, et al. Comparative study between result of temporalis muscle fascia and tragal cartilage perichondrium as a graft material in type 1 tympanoplasty. Int J Otorhinolaryngol Head Neck Surg 2018; 4:565-8.
15. Gun T, Boztepe OF, Atan D, Ikinciogulları A, Dere $H$. A comparison of cartilage palisades and temporal fascia in type 1 tympanoplasty for bilateral tympanic membrane perforations in children. J Int Adv Otol 2017; 13(1): 36-9. DOI: 10.5152/iao.2016.1855.

16. Siddique SM, Albina LSA. Cartilage tympanoplasty: A review on its postoperative/functional outcomes on hearing. J. Evid. Based Med. Healthc. 2016; 3(59), 3206-3211. DOI: 10.18410/jebmh/2016/695.

17. Kaya I, Benzer M, Uslu M, Bilgen C, Kirazli T. Butterfly cartilage tympanoplasty long-term results: Excellent treatment method in small and medium sized perforations. Clinical and Experimental Otorhinolaryngology. 2018; 11(1): 23-9. https://doi. org/10.21053/ceo.2017.00549.

18. Yegi $\square$ n Y, Yazııı ZM, Çelik M, Güneş S, Sayın I, Kayhan FT. Comparison of temporalis muscle fascia and fullthickness cartilage grafts in type 1 tympanoplasty. Int J Clin Exp Med 2016; 9(5):8731-8736.

\begin{tabular}{|c|c|c|c|}
\hline \multicolumn{3}{|c}{ AUTHORSHIP AND CONTRIBUTION DECLARATION } \\
\hline Sr. \# & Author(s) Full Name & Contribution to the paper & Author(s) Signature \\
\hline 1 & Fazal-I-Wahid & $\begin{array}{l}\text { Conceived, designed and } \\
\text { prepared the manuscript. } \\
\text { Did statistical analysis and } \\
\text { critically reviewed manuscript. }\end{array}$ \\
\hline 2 & Sajid Rashid Nagra & \\
\hline
\end{tabular}

